\title{
Birger Hedén
}

\section{Avsked och början: slutscenerna i Harry Kullmans ungdomsböcker}

Harry Kullmans författarskap för unga har haft stor betydelse för den moderna, realistiska ungdomsromanens framväxt i Sverige. 2009 skulle han ha fyllt 90 år. Det uppmärksammas här med en artikel om slutscenerna i några av ungdomsböckerna.

För drygt tjugofem år sedan disputerade jag på en avhandling med titeln Individ, våld och klassamhälle. En studie i Harry Kullmans ungdomsböcker (1983). I den berörs vid några tillfällen det som Kullman själv kallade slutscenen i sina böcker. Han sade sig ofta ha haft den som utgångspunkt, när han byggde upp handlingen. Framförallt analyseras i avhandlingen slutscenen mot bakgrund av motiven våld och klassamhälle. Kullman såg själv slutscenen som en förövning till det slutliga avskedet. Han menade att slutscenen var bärare av en vision:

Denna vision eller yttersta idé, manifesterar sig i det mer eller mindre maskerade avskedet. Ett avsked från oskuld, dröm, barndom, ett uppbrott från en plats, stad, ort; ett avsked av vänner, kamrater. Detta avsked har nästan alltid ett stänk av melankoli för egentligen är det inget annat än en förövning inför eller en försmak av det slutgiltiga avsked vi alla en gång måste ta. (Kullman 1968, 140)

I en artikel om hur Kullman inleder sina ungdomsböcker knyter jag också an till slutscenen (Hedén 1989). Nu vill jag uppmärksamma hur Harry Kullmans ungdomsböcker slutar, med fokus på just slutscenerna. Efter en kort sammanfattning av författarskapet följer några allmänna iakttagelser kring slutscenerna och en kort diskussion av de ändringar som gjordes $i$ en handfull nyutgåvor.

Tyngdpunkten i uppsatsen ligger på de avsnitt som kallats "Verklighet och (dag)drömmar" och "Trots allt: en början". Jag kommer att fokusera på förhållandet mellan realism och fantasi och hävdar att många av slutscenerna som blir allt mörkare i de senare böckerna ändå innehåller en början på något nytt.

Materialet består av Kullmans sjutton ungdomsböcker. Åtta av dem är vid olika tillfällen reviderade; också de utgåvorna beaktas. 


\section{Kullmans författarskap}

Harry Kullman (1919-1982) tillbringade sina första sju år i Malmö, men bodde sedan hela sitt liv iStockholm. Hans författarskap omfattar tjugotre böcker: varav sjutton är romaner för ungdom. Av de övriga är fyra romaner för vuxna. En av dem, Beundraren (1961) skrevs för ungdom men utgavs för vuxna och två var spänningsromaner. De båda övriga var dels en historisk framställning om vilda västern dels en självbiografisk bok som bland annat handlar om västernäventyr på film och om Kullmans besök i USA, Mannen från Montana (1970).

Handlingen i de av ungdomsböckerna som kan betecknas som realistiska utspelas i stor utsträckning på Södermalm i Stockholm i de kvarter där Kullman själv växte upp under 1920- och 30-talen. I några böcker beskrivs ett samtida Stockholm, Den svarta fläcken (1949), respektive Rio de Janeiro, Den amerikanske fången (1975). I hans ungdomsböcker är det alltid fråga om ett underifrånperspektiv, och oftast om ungdomar ur arbetarklass. Bland de mer framträdande teman som han behandlar bör nämnas klassolidaritet och barndomsupplevelser samt våld i verklighet, i fiktion och i populärkultur. Dessutom är det rent allmänt värt att påpeka något som inte har lyfts fram tidigare, nämligen de humoristiska inslagen i böckerna. De vore värda en egen uppsats.

\section{Några allmänna iakttagelser}

I min uppsats om Kullmans inledningar (Hedén 1989) konstaterar jag att dessa i de senare böckerna blir mer mångtydiga, samtidigt som slutscenerna i de fyra sista ungdomsböckerna med viss analogi erbjuder en "öppen" situation.

I tretton av böckerna presenteras huvudpersonen redan i inledningen. Föga oväntat förekommer däremot huvudpersonen (eller ibland huvudpersonerna) i samtliga slutscener - det torde å andra sidan vara svårt att hitta en ungdomsbok där så inte är fallet.

Inledningarna förläggs i böckerna allt senare under året, det är alltså under den mörkare årstiden som flera tar sin början. Med viss konsekvens är det sen eftermiddag eller kväll i tio av böckerna när slutscenen är allt som återstår av handlingen.

I ett par av böckerna - Den tomma staden (1951) och De rödas uppror (1968) - finns ett visst samband mellan inledning och slutscen. Tydligast är detta dock i vuxenromanen Beundraren (1961). Endast i tre av böckerna finns en tydlig anknytning mellan titel och inledning (Buffalo Bill 1955, Rymlingen 1957 och Spejarna 1958). Däremot återspeglas 
titeln i slutscenerna i hela tio av böckerna, alltifrån debutboken Med hemlig order (1948) till den sista, Stridshästen (1977). Med tanke på den vikt Kullman lade vid slutscenen är det inte så konstigt.

Hur är det med lyckliga och olyckliga slut? Om man ska vänta sig lyckliga slut(scener) i en ungdomsbok av lite äldre datum kan diskuteras. Det beror ju inte minst på vad man menar. Här definierar jag det lyckliga slutet som att något allvarligt inte har drabbat huvudpersonerna och att de blickar framåt med tillförsikt, även om ett visst vemod ibland kan märkas. I Kullmans fall kan man då tala om lyckliga slut i åtminstone åtta av de nio första ungdomsböckerna. Därefter blir det mörkare, för att kulminera med huvudpersonens död i Den amerikanske fången (1975) och en av huvudpersonernas död i Stridshästen (1977).

Ändå ska man inte tala om helt olyckliga slut eftersom det också finns något som motsäger mörkret. Vilket jag återkommer till sist i uppsatsen.

\section{Ändringar i slutscenen: från utopi till verklighet}

I artikeln "Slutscenen" som citerats skriver Kullman om slutscenens känsloladdade vision. Den visionen eller idén manifesterar sig i avskedet sägs det. Och det är ett mer eller mindre maskerat avsked. Artikeln skrevs när Kullman redan hade fått fjorton skönlitterära ungdomsböcker utgivna (jag inkluderar De rödas uppror som kom ut samma år som artikeln publicerades). Det innebär att han kunde betrakta sitt författarskap så långt med viss distans och därigenom formulera en helhetsuppfattning om slutscenens innebörd. Med tanke på den vikt han lägger vid slutscenen och sin vision kan man i första ögonblicket förundras över att han sedan ändrade i slutscenen i fem av sina sju första ungdomsböcker när de gavs ut på nytt. I ett par av dem blev sluten därmed dessutom radikalt annorlunda. Höll alltså inte visionen? Jo, det gjorde den. För det var bara i två böcker som slutet helt förändrades. Och i bägge fallen skedde det för att skapa större trovärdighet

När det gäller den ena slutscenen, i Den svarta fläcken (1949), får i originalversionen den unge Daniel som är medskyldig till bland annat några bilstölder och ett inbrott, hyra på ett fartyg mitt i natten utan några papper. På så sätt undkommer han med kaptenens hjälp att straffas och därmed slipper han se fram mot en tillvaro där han får svårt att skaffa sig arbete och lätt bli en grabb på glid, en som fått en svart fläck på sig.

Men i versionen från1963 tänker han anmäla sig hos polisen och därmed ta sitt straff. Det är onekligen ett rimligare slut. Det var föga 
sannolikt att en ung man vid den tiden kunde ta hyra på ett fartyg, genom att det råkade finnas en kapten till hands som såg mellan fingrarna.

I den andra boken, Ponnyexpressen (1955), väljer huvudpersonen, den unge Hugo, att stanna kvar på ponnystationen i en hård tillvaro i den amerikanska västern på 1860-talet. När boken omarbetades och gavs ut igen 1962, ska Hugo i stället börja arbeta på en bank, vilket hade framställts som ett möjligt alternativ för honom redan i originalupplagan. Det var betydligt sannolikare att han, en vek och dagdrömmande pojke, skulle passa in bättre på banken än bland råbarkade män i vildmarken.

Av Kullmans tio senare ungdomsböcker utgavs endast tre på nytt. Och i bara en av dem gjordes en - obetydlig - ändring just i slutscenen, nämligen i 1976 års version av Gårdarnas krig (1959). Det var ett tillägg allra sist av orden "långt i fjärran".

\section{Verklighet och (dag)drömmar}

I mina båda tidigare studier av Kullmans ungdomsböcker har intresset riktats främst mot individens förhållande till våld och klasssamhälle i kombination med frågor om lojalitet och svek, och med författarskapet som ram.

Men det finns också mycket annat att uppmärksamma, inte minst i slutscenerna, alltså det visionära, drömmarna, utopierna och symboliken.

Jag exemplifierar med Kullmans nio ungdomsböcker från 1950talet: två historiska, tre västern och fyra vardagsrealistiska romaner. De bildar en brokig väv, där drömmar, utopier, nostalgi i så gott som samtliga böcker blandas med medvetenhet om verklighetens realiteter. Här exempel på detta från fyra slutscener:

Nu behöver jag [Henry] inga som håller i mig - inte ens några drömmar. Och väggen bakom honom var varm och skön och han vände ansiktet mot solen och blundade och värken sjönk undan och han väntade och väntade och längtade efter hennes steg igen ... (Den tomma staden 1951)

Och då vände Hugo ansiktet mot bjälkarna men det regnade inte alls in utan i stället lyste solen ur Lymans bruna ögon och han hade sitt breda, hemlighetsfulla leende som kom Hugo att rysa och skälva men som också sände förväntningens kårar utefter hans rygg - för när Lyman log, då var det fara å färde, men bara för hans fiender, sällan för hans vänner och aldrig, aldrig för stallpojkarna som han basade för! (Ponnyexpressen 1955) 
Men så skuttade han [huvudpersonen Holger] tillbaka till balkongen och kikade för säkerhets skull över gårdshusets svarta tak. För det kunde ju hända att fakiren hade blivit försenad av en skorsten och kom just nu, innan han sprang upp den sista trappan till den bruna dörren som det stod JONSSON på. (Rymlingen 1957)

Bilen körde genom den ljusa juninatten, bort från Katarinaområdet, längs Götgatan och ner mot Slussen, och då förstod Henry att de skulle till en helt annan del av staden, långt från Söder, till ett nytt hem, en ny gård och en ny skola, där han skulle möta nya kamrater för vilka Helgonen och Hämnarna var föga mer än spännande namn och romantiska rykten om storslagna strider och heroiska bragder. (Gårdarnas krig 1959)

Hugo är som nämnts en orealistisk drömmare, som tror att han hör hemma i det hårda livet på prärien. Henry i Den tomma staden släpper å sin sida sina dagdrömmar och hoppas på verklighetens förälskelse. Holger fantiserar om en livs levande fakir. Henry i Gårdarnas krig uttrycker sin sorg över att gå okända öden till mötes, genom att mytologisera det gångna årets viktigaste händelser.

I anslutning till Kullmans böcker vill jag också citera en av de mer magnifika slutscenerna i en starkt självbiografisk vuxenroman också utgiven på 1950-talet. Den återfinns i Jack Kerouacs On the road, som i huvudsak skrevs redan våren 1951. När romanen äntligen fick en förläggare 1957 hade de riktiga namnen ersatts av fiktiva. Den av Kerouac högt beundrade Neal Cassady, som nämns i citatet nedan, kallas då för Dean Moriarty.

On the road översattes första gången till svenska 1959. I romanens allra sista stycke, i sann mening en slutscen, finns likheter med de ovan angivna inslagen i Kullmans slutscener. Här citerar jag ursprungsmanuset från 1951:

So in America when the sun goes down and I sit on the old brokendown river pier watching the long, long skies over New Jersey and sense all that raw land that rolls in one unbelievable huge bulge over to the West Coast, all that road going, all the people dreaming in the intensity of it, and in Iowa I know by now the evening-star must be drooping and shedding her sparkler dims on the prairie, which is just before the coming of complete night that blesses the earth, darkens all rivers, cups the peaks in the west and folds the last and final shore in, and nobody, just nobody knows what's going 
to happen to anybody besides the forlorn rags of growing old, I think of Neal Cassady, I even think of Old Neal Cassady the father we never found, I think of Neal Cassady, I think of Neal Cassady. (Kerouac 2007, 408)

Det är skymning, resan har nått sitt slut, visionen av ett Amerika med vägar, prärier, floder, bergstoppar och havsstränder målas upp med den allra lättaste antydan om livets slut.

Om Kullman hade läst Kerouacs roman vet jag inte. Men slutscenen i den omarbetade utgåvan av Buffalo Bill (1960) är en besläktad variant av denna vision, av detta tonläge, som också återfinns, om än svagare, i slutscenen i Gårdarnas krig året innan:

Buffalo Bill såg ut över västpalissadens taggiga kant mot Mullvadsbergens svepande båglinje som avtecknade sig mot en slocknande kvällssky och han kände ett djupt vemod över orden, för han visste, att det grymma kriget oundvikligen måste sluta med en stolt och tapper indianstams undergång och upplösning; men kanske, kanske samlades de åter i aftonrodnadens land och red över sälla jaktmarket - utom räckhåll för alla blekansikten - där bufflarna aldrig tog slut och där det knähöga präriegräset vajade svagt för slätternas eviga vind.

En så utförlig skildring av det som ligger efter det slutgiltiga avskedet, förekommer för övrigt bara i denna enda av Kullmans böcker, även om det antyds också i slutet på Den amerikanske fången (1975):

Men fönstret var en grön, mäktig havsvägg som var dunkelt genomskinlig och på andra sidan anade han rymden och befrielse från stövlarnas tyranni och han skulle handlöst slunga sig genom den gröna väggen som Santos och den skulle splittras i tusen fragment och han skulle sväva fritt under några oerhörda sekunder innan han föll in i ett mjukt och varmt mörker som skulle famna honom i evigheters evighet.

Just dessa visioner med klart poetiska drag, med bilder hämtade från naturen eller fantasien (dagdrömmar såväl som fiktionsinspirerade fantasier) återfinns i sex av de sjutton ungdomsböckerna (Buffalo Bill 1957, Gårdarnas krig 1959, Mannen från mörkrummet 1963, Fångarna på Fattigmannagatan 1972, Den amerikanske fången 1975 och Stridshästen 1977). De utgör grupp ett.

Romanslut av inte fullt så poetiskt slag men ändå med en tydlig känsloladdad ton finns i likaså sex böcker (Med hemlig order 1948, Den 
tomma staden 1951, Ponnyexpressen 1955 och framför allt utgåvan från 1960, Spejarna 1958, Boskapstjuvarna 1965 och De rödas uppror 1968), som utgör grupp två.

I de återstående fem böckerna, således grupp tre, är slutscenerna av mer faktiskt, konstaterande slag och i dem finns inte ens ett stänk av slutgiltigt avsked (Den svarta fläcken 1949, Den spanska värjan 1952, Hemlig resa 1953, Leve konungen 1956 och Rymlingen 1957).

Den här gruppindelningen bekräftar - men motsäger paradoxalt nog samtidigt - Stefan Mählqvists iakttagelse att "realismen får allt tydligare övertoner av symbolik och allegori" i Kullmans senare böcker (Mählqvist 1989, 117). Jag vill dock påpeka att Mählqvists karakteristik utgör ett omdöme om böckerna i deras helhet. Men den mer prosaiska tonen är mycket riktigt rådande $i$ alla de fem böckerna i grupp tre, utom i Hemlig resa, där det finns några avsnitt som påminner mer om till exempel Den tomma staden.

Samtidigt är det å ena sidan så att även böckerna i grupp två överlag är mer prosaiskt realistiska. Medan å den andra sidan böckerna i grupp ett med slutscener som jag håller för visionära med poetiska drag, faktiskt tillkommer under hela den tid som Mählqvist överblickar i sin sammanfattning.

Med andra ord är det inte riktigt så att realismen blir mer symbolisk och allegorisk endast under senare delen av författarskapet. För även om slutscenerna i Fångarna på Fattigmannagatan (1972) och Den amerikanske fången (1975) onekligen väl kan karakteriseras som symboliska, kan också en slutscen som den i Mannen från mörkrummet (1963) karakteriseras på samma sätt:

Herbert log för att han pratade högt. Nu hade han blandat ihop dröm och verklighet igen. Men han var inte riktigt säker på om han inte innerst inne ville ha det så för det var enda sättet för honom att hålla kvar den riktige Danell. Även om fienden lurat honom och sprängt honom tillbaka till ett fängelse bortom tid och rum så fanns han dock kvar om man blandade dröm och verklighet; en uppfinningsrik och outtröttlig fallen ängel med mäktiga kunskaper, en man som aldrig skulle ge sig utan ta sig till jorden igen och återuppstå någon gång, någonstans, i någon form.

\section{Trots allt: en början}

Så här långt kan sägas att Kullman fortgående i sitt författarskap för ungdom blir sin idé om avskedet trogen. Samtidigt finns också i just 
slutscenerna ibland något annat än vad som hittills diskuterats. Avskedets slutgiltighet får en mer eller mindre tydligt uttalad invändning, ett "trots allt", som i Stridshästen (1977): "Försiktigt klättrade jag ner från pappersbalarna utan att ta av mig hästhuvudet och förenade mig med mina kamrater hästarna."

Här innebär avskedet att huvudpersonen Roland väljer sida i klasskampen. Avskedet blir däremot en inledning till något nytt.

Hur mycket man vill läsa in i detta "trots allt" i en slutscen beror förstås på vilken ram man vill hålla sig inom. Jag kan till exempel inte finna att ett religiöst, eller rättare, kristet, perspektiv anläggs någonstans. Just i Mannen från mörkrummet talas visserligen om att en fallen ängel ska återuppstå, men det har ingenting med den kristna återuppståndelsen att göra. Däremot finns det en mycket tydlig vink om att den mäktige ska återkomma. Men i det här fallet rör det sig om ett möjligen ironiskt "trots allt". Stefan Mählqvist har i en fin analys av den här boken uppfattat fotografen och uppfinnaren Danell som ett slags Faustgestalt, för vilken vetenskapens nya landvinningar är allt och dess eventuellt förödande konsekvenser intet (Mählqvist 1989).

Med andra ord är den av huvudpersonen Herbert beundrade Danell en gestalt vars återkomst man kanske inte alls borde emotse med förväntan! Men som Mählqvist understryker: "Ondskan och godheten blir hos Kullman alltid subtilt mångfacetterad och sammansatt. " (Mählqvist, 78). Denna mångfacettering innebär alltså att Danell inte enbart är en mörkerman. I slutet av romanen kommer Herbert ihåg att fotografen vid ett tillfälle sagt något till honom, som går på tvärs mot bilden av Danell som en själlös Faust (och därmed sätter ett litet frågetecken för vad Danells egentliga mission faktiskt består i): "Vad hade fotografen sagt? Att man aldrig skulle ge upp, aldrig tappa taget för då blev blicken själlös, ögonen glanslösa och tomma. 'Då skrattar Satan! Då har han triumferat! '" (Mannen från mörkrummet, 188f.).

Redan i debutboken Med hemlig order (1948) innehåller slutscenen både ett avsked och en början. Avskedet är ett avsked till äventyret, med dess flykter, förföljelser, förräderiers och hemligheters avslöjande: "Stephan skrattade; de vände om och vandrade hand i hand upp mot slottet igen." Men den sista meningen lyder: "Båda drömde om den ljusa och rika framtid som låg framför dem - drömde, så som man skall drömma när man är ung och varje morgon är början på ett nytt stort äventyr." Här är det livet självt som står som det förnyande, som en invändning mot avskedet som metafor. I den omarbetade utgåvan från 1961 är emellertid meningen struken. Kanske fann författaren den alltför banal? Att detta inte behöver uttalas för den tänkande läsaren? 
I Den tomma staden (1951) beskrivs i slutscenen hur huvudpersonen tar avsked från sina drömmar och nu befinner sig i verkligheten med hull och hår och att drömmarna om kärlek förbytts mot en väntan och en längtan efter den flicka han äntligen upptäckt, fast hon så länge funnits mitt framför ögonen på honom.

En slutscen med en liknande förnyelse, en invändning mot avskedet (och därmed mot det som Kullman betecknade som melankoli, som kan anas i den sedermera strukna slutmeningen i Med hemlig order) återfinns i övrigt först i de omarbetade slutscenerna i Ponnyexpressen (1962) och Den svarta fläcken (1963). Därefter som nämnts i Mannen från mörkrummet, men också, och inte minst, i De rödas uppror (1968) där detta "trots allt" originellt nog sker i ett tillbakablickande berättarperspektiv: om huvudpersonen skulle handlat på annat sätt så hade det blivit mycket bättre på flera plan. Kanske inte mycket till motvikt mot hur det faktiskt blev, men ändå en vink om att det går att göra annorlunda. Dessutom tycker sig berättarjaget ibland ännu som vuxen skymta Palle i medier och "i storstadens vimmel", som en som alltjämt bekämpar samhälleliga orättvisor. Också i Fångarna på Fattigmannagatan (1972) finns Palle med, även om den vision som utgör slutscenen inte rymmer mycket till "trots allt". Och Palle själv framstår där i slutet som resignerad, som om kampen mot det onda och mot orättvisor kanske inte kommer att lyckas.

Med slutscenerna i de här båda böckerna i minnet är det lätt att se slutscenen i Stridshästen (1977) som en kommentar till dem. Den som så ofta ganska passive huvudpersonen i Kullmans böcker blir äntligen handlingskraftig. Han behöver inte längre lita till någon "Palle" som ställföreträdare. Den sista ungdomsbokens slutscen kan också ses som en reaktion på det mörker som både bildligt och bokstavligt råder i slutet på de båda nyss nämnda böckerna. Och äventyrens och dagdrömmarnas värld som redan i till exempel Den tomma staden (1951) och än kraftigare i Spejarna (1958) hade ifrågasatts, blir i Stridshästen slutgiltigt demaskerad när Roland med stort allvar förenar sig med sina kamrater hästarna. 


\section{Bibliografi}

Hedén, Birger. Individ, våld och klassamhälle: en studie i Harry Kullmans ungdomsböcker. Stockholm: Rabén \& Sjögren, 1983.

Hedén, Birger. "'Det var vår sista termin i skolan': hur Harry Kullman inleder en roman". I Författaren från Fattigmannagatan: en bok om Harry Kullman redigerad av Stefan Mählqvist.Stockholm: Rabén \& Sjögren, 1989.

Kerouac, Jack. On the road: the original scroll. New York: Viking, 2007.

Kullman, Harry. Beundraren. Stockholm: Rabén \& Sjögren, 1961.

--- Boskapstjuvarna. Stockholm: Rabén \& Sjögren, 1965.

--- Buffalo Bill. Stockholm: Rabén \& Sjögren, 1955. (ny rev. uppl. 1960).

--- De rödas uppror. Stockholm: Rabén \& Sjögren, 1968.

--- Den amerikanske fången. Stockholm: Rabén \& Sjögren, 1975.

--- $\quad$ Den spanska värjan. Stockholm: Rabén \& Sjögren, 1952.

--- Den svarta fläcken.Stockholm: Rabén \& Sjögren, 1949. (ny rev. uppl. 1963).

--- Den tomma staden. Stockholm: Rabén \& Sjögren, 1951.

--- $\quad$ Fångarna på Fattigmannagatan. Stockholm: Rabén \& Sjögren, 1972.

--- Gårdarnas krig. Stockholm: Rabén \& Sjögren, 1959. (ny rev. uppl. 1976).

--- Hemlig resa. Stockholm: Rabén \& Sjögren, 1953.

--- $\quad$ Leve konungen. Stockholm: Rabén \& Sjögren, 1956.

--- Mannen från Montana. Stockholm: Rabén \& Sjögren, 1970.

--- Mannen från mörkrummet. Stockholm: Rabén \& Sjögren, 1963.

--- $\quad$ Med hemlig order. Stockholm: Rabén \& Sjögren, 1948. (ny rev. uppl. 1961).

--- Ponnyexpressen. Stockholm: Rabén \& Sjögren, 1955. (ny rev. uppl. 1960, 1962).

--- Rymlingen. Stockholm: Rabén \& Sjögren, 1957.

--- "Slutscenen". I Skolbiblioteket (1968) 4.

--- Spejarna. Stockholm: Rabén \& Sjögren, 1958.

--- Stridshästen. Stockholm: Rabén \& Sjögren, 1977.

Mählqvist, Stefan, "Utsikt från en bakgård: Harry Kullmans författarskap i tidshistorisk belysning". I Författaren från Fattigmannagatan: en bok om Harry Kullman. redigerad av Stefan Mählqvist. Stockholm: Rabén \& Sjögren, 1989.

Keywords: Harry Kullman 